\title{
An empirical research on the components of postgraduate innovative ability
}

\author{
Xiangsheng Meng* \\ School of Economics and Management, Hebei University of Technology, Tianjin, China \\ xshm@hebut.edu.cn
}

Keywords: Graduate student; Innovative ability; Postgraduate innovative ability; Influence factor

\begin{abstract}
Postgraduate innovative ability is one of the important abilities which postgraduate students should have. This paper discusses the connotation and influence factors of postgraduate innovative ability, which divides innovative ability into several practical abilities: innovative consciousness, scientific research ability, innovative practice ability, innovative spirit, innovative thinking, innovative methods and skills, innovative quality, innovative personality and wisdom, technical application ability, organizing ability and the team cooperation ability. The practical abilities are sorted and analyzed by theoretical analysis and empirical research, .Countermeasures and suggestions are given for postgraduate innovative ability training.
\end{abstract}

\section{Introduction}

In this paper, postgraduate students refers to full-time postgraduate students. In recent years, China recruits more than half a million postgraduate students each year. The development of postgraduate education cannot keep pace with the booming enrollment and the development of discipline, which leads to postgraduate students' quality reduction and low innovative ability, which seriously affects the sustainable development of postgraduate education. Postgraduate innovative ability is an important index to measure the level and quality of postgraduate education. How to improve the quality of postgraduate education, accelerate the strong innovative ability of Chinese postgraduate students team, become an important topic and task for the management of postgraduate education in our country. Thus, defining the components of postgraduate innovative ability, discussing the formation mechanism of postgraduate innovative ability have important theoretical and realistic significance to the targeted training of postgraduate innovative ability and realizing postgraduate innovative ability's constant improvement.

\section{The connotation and the components of postgraduate innovative ability}

There are various definitions of postgraduate innovative ability. From different points of view, many scholars give the connotation of postgraduate innovative ability. Zhang [1] defines the connotation of postgraduate innovative ability as: individuals' ability to carry out creative activities by using fundamental and subject frontier knowledge and available materials. The core of it lies in the breakthrough and unique insights, representing as owning the ability to produce some new and unique idea, viewpoint, method or product, which has social value or individual value. In [2], Xie regards postgraduate innovative ability as postgraduate student's creative potential in his research field. Sun [3] thinks that postgraduate innovative ability is the knowledge innovative ability in his academic frontiers field. Ding [4] points out that postgraduate innovative ability does not only include creative learning ability, thinking ability and process capability, such as practical skills, but also includes the potential creative intelligence which is gradually acquired through the process of learning and working, such as the basic knowledge and experience, creative personality and cognitive style and so on. Meng [5] studies the training of postgraduate innovative ability. 
In [6], Qu divides postgraduate innovative ability into five types: self-learning ability, research ability, interpersonal skills, research design ability, the ability of controlling frontier. Liu [7] thinks that postgraduate innovative ability includes innovative spirit, innovative thinking and innovative method. Pan [8] thinks that postgraduate innovative ability should include rich broad basic knowledge, keen thinking ability, comprehensive intellectual development, good personality and strong research motivation. Zhang [1] thinks the basic component of postgraduate innovative ability includes innovative passion, innovative practice and innovative quality. Xie [2] points out that postgraduate innovative ability includes basic knowledge, basic theory and basic ability in professional field, creative thinking and research ability, creative cognitive strategy and style. Ye [9] argues that postgraduate innovative ability mainly includes knowledge structure, innovative consciousness, innovative thinking and innovative practice. Huang [10] thinks that postgraduate innovative ability include knowledge structure, innovative thinking and innovative personality.

Based on the above summary about the connotation and influence factors of postgraduate innovative ability, this paper proposes the understanding of postgraduate innovative ability.which can be divided into several practical abilities: innovative consciousness, scientific research ability, innovative practice ability, innovative spirit, innovative thinking, innovative methods and skills, innovative quality, innovative personality and wisdom, technical application ability, organizing ability and the team cooperation ability. These practical abilities are respectively labeled from ability 1 to ability 11 in the following.

According to the questionnaire, this paper sorts these practical abilities, and studies their importance. In this paper there are 108 valid samples (postgraduates), including students in the institutes of management, humanity and law, chemical industry, and civil engineering, each has 40, 21, 28, 19 samples, respectively.

\section{Results and discussions}

The questionnaire design includes two parts. The first part investigates students basic situation and the motivation of studying. The second part investigates postgraduate students understanding of innovative ability and its formation mechanism. The questionnaire design use Likert-type scale. This paper mainly analyzes postgraduate students in different disciplines whether have different realization on innovative ability. This paper investigates the relative importance of each index by the mean value given by each institute. This paper also considers personal characteristics' influence on the formation mechanism of postgraduate innovative ability.

\section{The motivation for being a postgraduate}

It can be seen from the questionnaire that for both male and female postgraduate students, their motivation mainly concentrate in finding a good job after graduation, over $60 \%$ of postgraduate students select this motivation, furthermore, more than $80 \%$ schoolgirl select this motivation. This reflects China's present basic situation of students' employment, that is, students are facing with grim employment situation, especially for female students. In addition, about $21 \%$ postgraduates select the motivation "enjoy research work" and about $17 \%$ postgraduates select " improve one's academic level". This indicates that part of postgraduates want to level up their academic research level. From the above, it can be seen that there are distinct motivation for being a postgraduate. From this perspective, postgraduate education should keep pace with it, the educational objective should not only be academic research as before, the educational objective should also pay more attention on postgraduate employment. In addition, from the postgraduate student's academic features' points of view to see the motivation, $87 \%$ humanity and law postgraduate students select the motivation to finding a good job after graduation, this high concentration is consistent with the grim employment problems of this subject. Engineering postgraduate students' motivations are relatively scattered, 
according to the selected proportion they are: finding a good job after graduation (52\%), improve one's academic level (21\%), enjoy research work (17\%), job demand (7\%), others $(3 \%)$.

Postgraduate students understanding of postgraduate innovative ability. According to the questionnaire, the mean value of these practical innovative abilities given by postgraduates in four institutes can be obtained. The following figure shows the mean values (Fig. 1).

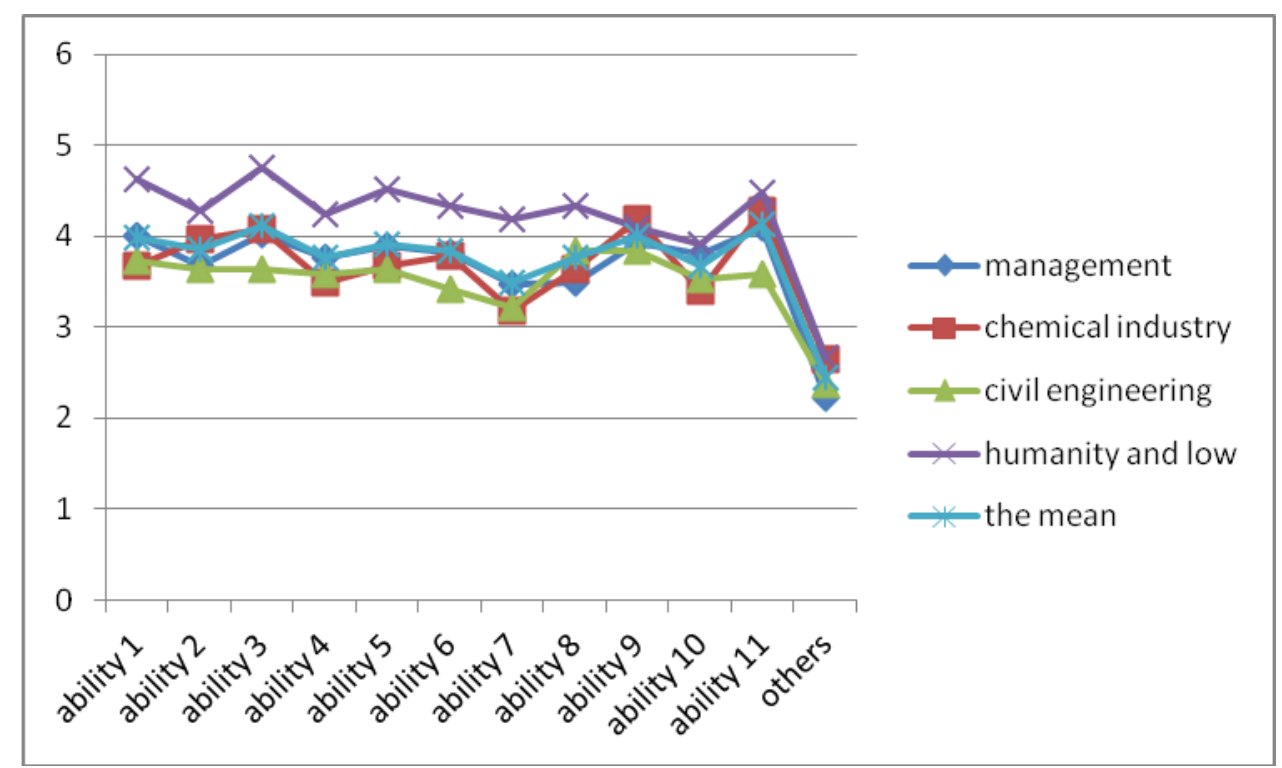

Fig. 1 The mean of the practical postgraduate innovative abilities

Through the survey statistics, it can be seen that postgraduate students consider innovative practice ability and team cooperation ability as the most important abilities, one of which reflects postgraduates' ability of creatively transfer their knowledge to practice ability and the other of which reflects postgraduates' ability of cooperating with other team members to make innovation. This result really reconfirmed with the fact that most postgraduates' motivation for being postgraduate is finding a good job after graduation, which shows that most postgraduate students think that using their knowledge to make innovative practice is one of the most important innovative ability. In addition, most postgraduate students aware that team cooperation ability plays an important role in improving individual innovative ability. Therefore, in the process of postgraduate education, to improve postgraduate student's innovative practice ability and the team cooperation initiative and self-consciousness is an important and urgent practical problem. Of course, technical application ability, innovative consciousness, innovative thinking are factors with higher recognition. These reflects that postgraduate students pay close attention to developing technical application ability, innovative consciousness and innovative thinking.

By studying on questionnaire data, it can be seen that innovative ability training which postgraduate students of different disciplines focusing on has certain differences. For example, the chemical industry and civil engineering postgraduate students give higher score on scientific research ability than the score given by the students of management and humanity and law, which reflects that postgraduate students can train their scientific innovative ability through scientific research. This factor is needed to be strengthened in the process of current engineering postgraduate education.

Analysis on the influence factors forming postgraduate innovative ability. At the same time, the questionnaire investigates the influence factors forming postgraduate innovative ability. These influence factors can be divided into five aspects: innate factor, acquired factor, individual learning, cultivation by supervisor, organization cultivation by subject, school and so on (briefly called organization cultivation). According to the questionnaire, the mean value of these aspects given by postgraduates in four institutes is obtained. The following figure shows the mean values (Fig. 2). 


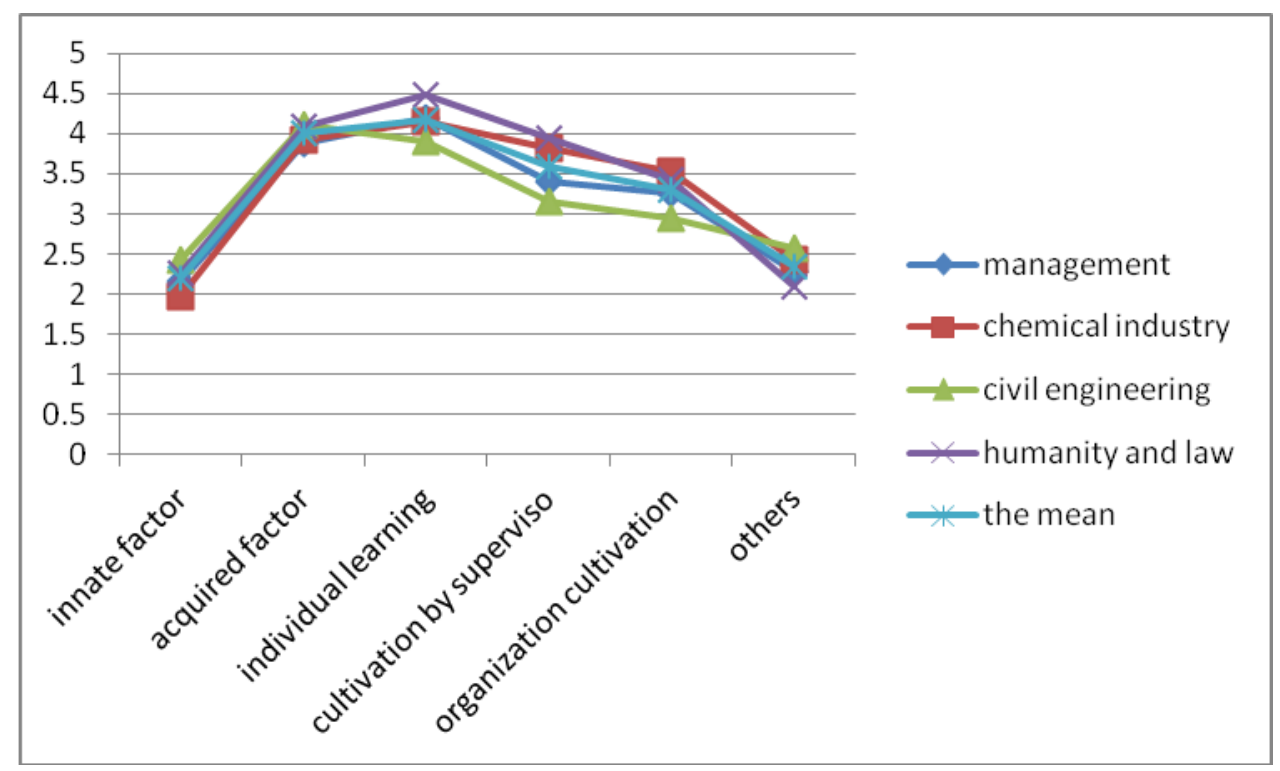

Fig. 2 The mean of the influence factors forming postgraduate innovative ability

From the result of the questionnaire, it can be seen that postgraduate students think that the most important influence factors forming postgraduate innovative ability are individual learning, acquired factor and cultivation by supervisor. Most postgraduate students believe that postgraduate innovative ability can be obtained by acquired learning. Although innate factor can determine the difference of the training of postgraduate students, its has comparatively little affect on postgraduate innovative ability. By the questionnaire, it shows that most postgraduate students think that individual learning is the most key factor for postgraduate innovative ability education. In addition, to individual learning, supervisor's cultivation and organization cultivation also play important roles in postgraduate innovative ability education which should not be ignored.

\section{The conclusion and suggestions}

From the above analysis, the results of the questionnaire basically reflect problems existing in current process of postgraduate innovative ability education. The questionnaire survey also embodies postgraduate students understanding of postgraduate innovative ability. Thus, the investigation can be considered to be successful. According to the questionnaire survey, the conclusion is as follows: postgraduate innovative ability training process is a process with multi-actor participation. In the cognition aspect of postgraduate innovative ability connotation, innovative practice ability and the team cooperation ability are the two important abilities in postgraduate innovative ability. Among the various influence factors forming postgraduate innovative ability, postgraduate students think that the most important influence factors are individual learning and acquired factor. Postgraduate student innovative ability training mainly depends on graduate students' individual efforts. It can be said that the obtaining of postgraduate innovative ability depends mainly on acquired learning, but not mainly on innate factor, which means postgraduate innovative ability can be obtained by acquired learning. In addition, there are different understanding of postgraduate innovative ability by postgraduate students of different disciplines, which may cause the attention of the relevant principals of postgraduate education.

In order to promote postgraduate innovative ability and to improve the quality of postgraduate education, it is proposed that the related organizations of postgraduate education should focus on the following several aspects: 1) Do ideological-political work well and improve postgraduate students' learning activeness and enthusiasm. 2) Construct a supervisor team with higher academic standards. Supervisor's guidance has great influence on the process of postgraduate training. A highly respected and with profound knowledge supervisor's influence on postgraduate students will 
bring them a life-long benefits. 3) Classifying cultivating postgraduate is necessary to postgraduate innovative ability training. In the process of postgraduate innovative ability training, targeting training should be given according to postgraduate characteristics. 4) Improve the links of graduate education, construct a scientific supervision mechanism of postgraduate student training. Discipline and the college should play an important role in the process of postgraduate innovative ability. School management and other organizations should create conditions for the training of postgraduate innovative ability.

\section{Acknowledgement}

This research was supported by ZH2011206.

\section{References}

[1] J.L. Zhang, Exploration on graduate cultivation mechanism reform based on innovative ability, China Higher Education Research. 3(2008) 34-38.

[2] A.B. Xie, Cultivate doctoral students' innovative ability combining with a variety of channels, China Higher Education. 20(2007) 33-35.

[3] C. Sun, Research on the feature analysis of the innovative ability of graduate students, Journal of Higher Education. 8(2005) 62-65.

[4] H.Y. Ding, S.B. Ding, Postgraduate innovative ability and its formation, China Electric Power Education. 6(2006) 18-22.

[5] X.S. Meng, The demonstration on the training of postgraduate innovative ability, International Conference on Logistics Engineering, Management and Computer Science. (2014) 99-102.

[6] H.D. Qu, W.Z. Chen, Innovation competence for graduates: structure and difference, China Higher Medical Education. 1(2003) 29-31.

[7] Y.X. Liu, S.L. Tan, Q. Zhong, and H. Liu, Measures to cultivate the creativity of graduate students, Journal of Jiangxi Agricultural University. 2(2005) 90-92.

[8] L. Pan, S.M. Ji, and C.D. Lu, The cultivation of creative talents based on the innovation education platform, Heilongjiang Researches on Higher Education. 143(2006) 124-126.

[9] H.Z. Ye, and N. Ding, The graduate student innovation ability training strategy based on tacit knowledge, China Higher Education Research. 1(2008) 132-135.

[10] B. Huang, Y.Q. Ding, and D.S. Luo, The analysis on graduate students' innovative ability, Journal of Jiangsu Polytechnic University. 9(2008) 67-69. 